\title{
O CORDEL FILOSÓFICO DE MEDEIROS BRAGA: significação e cultura THE PHILOSOPHICAL CORDEL OF MEDEIROS BRAGA: meaning and culture.
}

\author{
Prof. - Dr. ${ }^{\text {a }}$ Renata Pinto Uchôa de Araújo \\ Programa de Pesquisa em Literatura Popular-PPLP/UFPB \\ renataolipinto@gmail.com
}

Resumo. Utilizando os pressupostos teóricos da Semiótica, este trabalho tem por objetivo geral analisar as significações culturais presentes na literatura popular escrita, convencionalmente chamada folheto de cordel. Realizamos uma discussão teórica acerca da Semiótica das Culturas, do ponto de vista da linha francesa de estudos semióticos. Examinamos, no folheto de cordel "Sócrates vida em morte em cordel", da autoria de Medeiros Braga, o percurso da significação, destacando as seguintes categorias semióticas: a busca dos sujeitos semióticos pelos seus valores; a natureza da enunciação (enunciativa, enunciva e híbrida); as zonas antrópicas onde os sujeitos estão inseridos (de identidade, de proximidade e de distanciamento culturais), a actorialização, a situação espaçotemporal; os conflitos e a natureza dos seus agonistas, tanto eufórica quanto disforicamente construídos.

Palavras-chaves: Semiótica das Culturas - cordel - significação.

Abstract. Using the theoretical assumptions of Semiotics, this work has as general objective to analyse the cultural meanings present in the popular written literature, conventionally called cordel leaflet. We hold a theoretical discussion about the Semiotics of Cultures, from the point of view of the French line of semiotic studies. We examine the path of signification in the string booklet "Socrates, Life in Cord Death", by Medeiros Braga, highlighting the following semiotic categories: the search of semiotic subjects for their values; the nature of enunciation (enunciative, enunciated and hybrid); the anthropic zones where the subjects are inserted (of identity, proximity and cultural distance), the actorialization, the space-time situation; the conflicts and the nature of their agonists, both euphorically and poorly constructed.

Keywords: Semiotics of Cultures - cordel leaflet - meaning.

\section{Semiótica, significação e sentido.}

A Semiótica contemporânea considera o texto como um signo. Segundo Rastier(2009, p. 30)ela "herdou das ciências da linguagem uma certa repugnância para tratar o texto e privilegiou o signo ,lugar de referência, assim como a proposição, lugar de verdade"; esquecendo a complexidade da diferença entre o signo e o texto, impede "pensar na incidência do texto sobre seus signos" .Para o autor(id. Ib.p.29) a Semiótica contemporânea continua a se deter na significação do signo, não no sentido do texto, ou seja, "conceito de semiótica ainda é o signo". A problemática maior que daí resulta é o fato de o signo não se estudar isolado, mas sim, em meio às práticas semióticas, que os apresentam em formações completas, sendo difícil seu fracionamento. Nas palavras de Courtès (1979, p. 41): 


\begin{abstract}
"A semiótica (...) tem por objetivo a exploração do sentido. Isto significa, em primeiro lugar, que ela não se reduz somente à descrição da comunicação (...): ela deve igualmente dar conta de um processo muito mais geral, o da significação".
\end{abstract}

A significação vai mais além: questões ignoradas pela comunicação são levadas em consideração pela significação e podem transmitir alguma forma de comunicação, como objetos, por exemplo, que podem comunicar sentimentos os mais diversos.

Vale ressaltar, ainda, que "a significação é uma propriedade definida para os signos e o sentido uma 'propriedade' dos textos"(Rastier, 2009, p.33). Isolado, um signo não tem sentido e um texto fica sem significação. A significação está ligada à descontextualização, já o sentido, à máxima contextualização da língua e da situação.A questão levantada é o fato de a Semiótica produzir teorias da significação, enquanto que a Semântica se ocupa com a produção dos sentidos, quando analisa os textos. Os problemas do sentido e da significação devem ser esclarecidos, fundamentando-se na Linguística.

Como meio de comunicação, o sentido aparece conforme uma relação entre sujeitos. Já como meio de representação, o sentido é considerado como uma relação entre o sujeito e o objeto. A significação é apresentada como uma relação; o sentido, por sua vez, é representado por um percurso. Rastier( 2009, p.34) concebe a significação "como uma relação entre correlatos externos do signo: o conceito e o referente, enquanto que sentido, define-se através de um percurso entre os planos de expressão e conteúdo, dentro do texto. 0 autor completa:

Esse percurso é um processo dinâmico que obedece a parâmetros variáveis conforme as situações particulares e as práticas codificadas pelos gêneros e os discursos; dessa forma, o sentido não é dado, mas resulta de um percurso interpretativo norteado por uma prática. ( 2009, p. 34).

Considerando a produção de sentidos como uma formação significativa, Greimas(1977) concebe a descrição desta por meio de um percurso gerativo, que vai do mais simples e abstrato até o mais complexo e concreto. Nas palavras de Fiorin (2005, p. 20):

o percurso gerativo de sentido é uma sucessão de patamares. Cada um dos quais suscetível de receber uma descrição adequada, que mostra como se produz e se interpreta o sentido, num processo que vai do mais simples ao mais complexo. 
Esse percurso, levando em consideração a organização do discurso, constrói um modelo que pode ser realizado em qualquer unidade textual, ou seja, em textos de natureza diversa: verbais, não verbais ou sincréticos. Essa previsibilidade é percebida através da descrição da significação em três etapas ou níveis de organização, cuja terminologia é inspirada em Chomsky. São eles: o Nível Fundamental que corresponde à instância inicial do percurso que gera a significação, e apresenta as oposições semânticas básicas que constroem o discurso; o Nível Narrativo, que comporta o fazer de um Sujeito semiótico em busca de seu Objeto de valor, motivado por um Destinador, auxiliado por um Adjuvante ou prejudicado por um Oponente; e o Nível Discursivo, que funciona sobre a relação entre os sujeitos discursivos, cujas escolhas possibilitam a conversão da narrativa em discurso (BATISTA, 2001).

\section{A semiótica das culturas e o entorno humano.}

A semiótica das culturas é considerada uma ciência da interpretação, pois é por meio da linguagem que o homem tem uma memória social, torna-se ciente de sua identidade cultural e do seu poder-fazer no mundo. Nas palavras de Pais:

A riqueza do homem é a sua diversidade linguística, cultural, social e histórica. Como se sabe, a língua e seus discursos, juntamente com as semióticas não-verbais e complexas, conferem a uma comunidade humana: a sua memória social; a sua consciência histórica; a consciência de sua identidade cultural e de sua permanência no tempo. (PAIS, 2009, p. 25).

Trata-se da ciência que proporciona o estudo da cultura humana, bem como, de sua pluralidade. Pela diversidade linguística, o homem se diferencia dos demais animais e a linguagem é o que lhe confere a qualidade de ser homem, ou seja, detentor de uma cultura, de uma história, de uma socialização. Assim, a semiótica das culturas estuda esse processo histórico da humanidade e a diversidade linguística e cultural que ela possui.

A comparação com outras culturas em oposição faz-se necessária para caracterizar-se uma cultura. 0 que resulta desse confronto de culturas, na verdade, são saberes e valores compartilhados. A cultura se transforma, desenvolve-se, desaparece, em torno de comparações com outras culturas. Sendo assim, interessam à semiótica das culturas, análises interpretativas, baseadas em comparações entre a culturas. Veja-se o que diz Pais (2009) sobre o assunto: 
Caracteriza-se uma cultura por suas especificidades, perante a diversidade das culturas humanas. É necessário considerar como características de uma cultura, definidoras de identidade e de diversidade, em relação às demais, como parte do "saber compartilhado sobre o mundo" de seus membros, o mundo semioticamente construído, o sistema de valores, o sistema de crenças. (PAIS, 2009, P. 26)

Rastier, em seu livro Ação e sentido por uma semiótica das culturas (2010)ํㅜ, afirma que os estados internos do sujeito não são representações, mas apresentações, porque mostram "associações específicas entre o indivíduo e seu entorno" (2010, p. 18-19). Níveis de apresentação e níveis semióticos compõem esse entorno e os níveis fenofísicos aparecem quando expõem uma incidência nas apresentações. Cada um desses níveis corresponde às três práticas seguintes (RASTIER, p. 20): a praxeologia representacional, que se situa mais em nível intelectual, como o raciocínio, por exemplo; a praxeologia semiótica, referente à geração e interpretação dos desempenhos semióticos e a praxeologia física, interessada pela atividade técnica e produtiva".

Cada prática social equivale a um discurso que, por sua vez, divide-se em tipos textuais (orais ou escritos). Estes sempre revelam um gênero, além de representarem a parte semiótica de um percurso de ação. Por exemplo, a literatura popular é uma prática que se divide em textos orais (o romance e os contos orais, a cantiga, a cantoria de viola) e escritos (o gênero cordel).

O nível semiótico do entorno humano, segundo Rastier (2010, p. 21) é caracterizado por quatro rupturas: a pessoal, a temporal, a espacial, e a modal, que são distintas por oposições linguísticas, "devendo qualquer enunciado estar situado, em pelo menos, uma das zonas que elas delimitam", que são: a identitária (do entorno do sujeito enunciador), a proximal (do entorno do sujeito enunciatário) e a distal (do entorno do ele que se encontra longe do enunciador e do enunciatário). No quadro a seguir, o autor resume as três zonas, distribuindo os elementos gramaticais que as caracterizam através das quatro rupturas anteriormente mencionadas:

Quadro 1: Zonas delimitadoras das rupturas

\footnotetext{
1 Tradução de Maria de Fátima B. de M. Batista.
} 


\begin{tabular}{c|c|c|c}
\hline & Z. identitária & Z. proximal & Z. distal \\
\hline Pessoa & EU, NÓS & TU, VÓS & ELE, SE, ISTO \\
\hline Tempo & AGORA & RECENTE & PASSADO \\
& EM SEGUIDA & FUTURO \\
\hline Espaço & AQUI & ALI & $\begin{array}{c}\text { LÁ, ACOLÁ } \\
\text { ALHURES }\end{array}$ \\
\hline Modo & CERTO & PROVÁVEL & $\begin{array}{c}\text { POSSÍVEL } \\
\text { IRREAL }\end{array}$ \\
\hline & \multicolumn{3}{|c}{ Fr. empírica fr. transcedente } \\
\hline
\end{tabular}

Fonte: Rastier, 2010, p. 23.

A principal ruptura, segundo o autor, separa as duas primeiras zonas da terceira e, assim, "separam-se um mundo óbvio (formado das zonas identitária e proximal) de um mundo ausente (estabelecido pela zona distal)" (RASTIER, 2010, p. 23).

Comparando-se com a linguagem dos animais, a linguagem humana tem a vantagem de remeter ao que está ausente no tempo e no espaço, fora da articulação entre o eu e o tu; pode situar-se, portanto, num tempo futuro ou passado e num espaço longínquo. Dando como exemplo a linguagem das abelhas, percebe-se que ela só acontece em um tempo presente e no espaço aqui. Uma abelha não tem capacidade de deixar registrada a experiência que fez no presente e transmiti-la para o futuro ou em outras colmeias.

Duas fronteiras se situam entre as três zonas: a fronteira empírica, localizada entre a zona identitária e a proximal; e a transcendente, ocorrida entre as duas primeiras e a distal. Os objetos da fronteira empírica foram chamados de fetiches pelo autor, e os da fronteira transcendente, ídolos (RASTIER, 2010, p. 29). São exemplos dos primeiros tipos de objeto: ferramentas, bonecas; e do segundo: rituais, obras de arte etc.

A linguagem, segundo o autor, pode ser detectada nas duas fronteiras, porquanto pode ter um uso com fins de divertimento, como para as crianças, mas, também, exercer a função de ídolo quando manifestada em obras artísticas, códigos de leis etc. Vale destacar que os percursos de enunciação e compreensão consistem em passagens constantes de uma zona a outra.

Análise do folheto Sócrates: vida e morte em cordel. 
Medeiros Braga, autor do folheto em questão, , além de ser formado em Economia, é romancista e poeta de bancada, nome que se dá ao poeta popular que faz poemas escritos e os publica em folhetos, diferentemente do cantador cujos poemas são oralizados em espetáculos performativos chamados cantorias Sendo um militante político de esquerda, sua preocupação sempre foi uma conscientização política através da educação, por isso suas obras possuem uma temática diversificada, permeando temas como história, geografia, filosofia, dentre outros. Além disso, também lhe é característico ser memorialista. Vastas são suas obras sobre biografias, tais como Paulo Freire, Patativa do Assaré, Zumbi dos Palmares, Ariano Suassuna, Sócrates. Por sua vasta e importante obra, tornou-se, em 2013, membro da Academia Brasileira de Literatura de Cordel (ABLC) .

O folheto Sócrates: vida e morte em cordel é uma biografia resumida do grande pensador grego que deu vasta contribuição para a filosofia e para a democracia, atingindo várias gerações. De origem humilde, aprendeu do pai o ofício de escultor, mas não seguiu a carreira; preferiu dedicar-se à filosofia, diferenciando-se dos demais colegas filósofos por lutar pela ideia de que o Estado só seria pleno se o povo se tornasse, de fato, cidadão. Para isso, dedicou a vida a formar cidadãos cientes de seus direitos e deveres, o que atraiu a ira dos poderosos, que lhe arquitetaram uma severa punição, culminando em sua morte.

Considerando as relações intersubjetivas, observa-se que o sujeito enunciador encontra-se pressuposto no texto e, portanto, numa zona de distanciamento dos acontecimentos enunciados, numa debreagem enunciva, atestada pela presença de verbos na terceira pessoa e nos tempos passado e presente. Em dado momento, o texto, introduz uma enunciação enunciada: nas últimas estrofes do folheto, o enunciador dá a voz a alguns atores, numa tentativa de ressaltar a tristeza que emanava entre os seus seguidores pela injusta condenação a que fora acometido o sábio grego. 
"Ele por vezes clamava

Aos deuses, religião,

Que às estrelas do Estado

Atrelavam sua missão;

Como um filósofo augusto

Não admitia que, injusto,

Houvesse um deus sem razão"
"E se virando aos discípulos

Tomados pela emoção

Ele diz: 'me traga o cálice

E a cicuta em proporção

Para que eu possa, sereno, Ingerir esse veneno

Para a minha execução"

Os sujeitos semióticos são discursivizados por atores específicos (indicados pelo nome próprios) e genéricos (apontados pelo papel temático ou função social que exercem). Gostaríamos de destacar, em particular, Sócrates, os seus pais e os inimigos do filósofo, que tramaram a sua condenação. Sócrates é o ator principal, a partir dele todos os acontecimentos da narrativa são gerados. Seu objeto de valor principal era vencer a ignorância. Utiliza-se do método dialético da indução processo de raciocínio ou argumento que parte de premissas particulares para uma conclusão geral ou universal, ou seja, a conclusão é sempre maior do que as premissas. Embora o método indutivo seja amplamente utilizado pela ciência atual, é um método falacioso, pois, ainda que as premissas sejam verdadeiras, a conclusão não se dá por necessidade lógica, consequentemente, nunca poderemos saber se a conclusão é verdadeira, para auxiliá-lo nessa luta. Seu público alvo eram os jovens, a quem quer fazer refletir sobre a situação a seu redor e a não aceitar, passivamente, o que lhes era imposto pelo Estado.

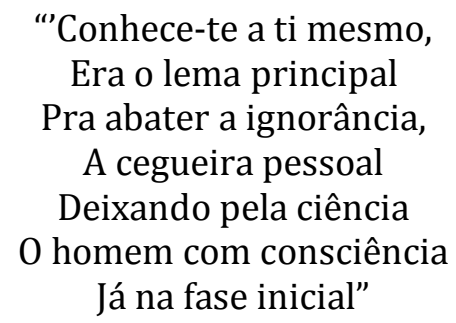

Os pais de Sócrates, por sua vez, esforçaram-se para tornar o filho um grande pensador, seu objeto de valor principal. Mesmo de origem e vida humildes, isso não foi impedimento para dar amor e uma boa educação ao jovem. Com certeza, ter pais íntegros e presentes reflete, positivamente, em toda a vida dos filhos. Com Sócrates não foi diferente, tanto que a instigação por parte dos pais de 
torna-lo um bom pensador o fizeram-no dar seus próprios passos em busca do saber.

"Sua mãe era parteira

Era seu pai escultor

Fenarete e Sofronisco

Que lhe deram muito amor,

Como ainda a condição

De ter uma educação

Para ser bom pensador"

Meleto, Demócrito e Licon representavam a aristocracia grega, não muito satisfeita com Sócrates, porque questionava o funcionamento da sociedade, até da religiosidade e propagava esses ideais para a população através do diálogo e pela inteligência e eloquência que despertavam interesse nos jovens, angariando muitos discípulos. Considerando-o como um agitador pela elite, os três arquitetaram uma severa punição a Sócrates. Recebendo a adjuvância dos juristas e poderosos, a condenação de Sócrates foi formalizada e a punição, efetivada, findando com a vida do grande filósofo. 


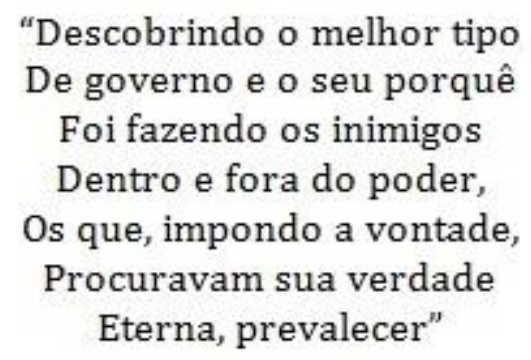

"Descobrindo o melhor tipo

e governo e o seu porque

Foi fazendo os inimigos

Dentro e fora do poder

Os que, impondo a vontade,

Eterna, prevalecer"

\author{
"Meleto, Anitos e Licon, \\ $\mathrm{Na}$ maior servilidade, \\ Indispôs Sócrates à lei \\ Acusando com inverdade \\ De negar o deus à pátria \\ De por um outro na área, \\ Corromper a mocidade"
}

No que concerne à situação espaço-temporal, no texto em questão, o que predomina é o espaço específico, que é composto por: Grécia; Atenas; Potideia; Tribunal da Inquisição. Tais localidades representam o lugar onde ocorreram os acontecimentos, informando o metaespaço, Grécia, a cidade natal de Sócrates, Atenas. Dentro desse metaespaço, escolhia localidades inespecíficas para propagar seus ideais, configurando o que aqui chamamos espaços genéricos: praças, ginásios, mercados. Estes são destacados também no passo-a-passo detalhado que realiza antes de morrer, na prisão, retornando do banheiro quando recebeu a notícia de que iria ingerir o veneno, que foi preparado na cozinha. Alguns exemplos são demonstrativos:

\author{
"Dialogando nas praças, \\ Nos ginásios e mercados \\ Ia seu público aumentando \\ De jovens abnegados \\ Com vontade de beber \\ Nessa fonte de saber \\ Conhecimentos primários"
}

\begin{abstract}
"Na prisão, em dada hora, Retornando do banheiro, Acompanhado de Críton, Seu mais leal companheiro Conversavam, caminhando Quando logo vão parando Para ouvir o carcereiro"
\end{abstract}

A organização da narrativa através das marcas de tempo mostram expressões como: dois milênios e meio, referente ao período em que ocorreram os fatos; 470 a.C., ano de nascimento de Sócrates; 30 dias, intervalo de tempo entre a sua prisão e execução.

\footnotetext{
"Era Sócrates o seu nome Nascido na velha Atenas, Em quatrocentos e setenta, Antes de Cristo, ele encena. Cuidou só em dialogar Com o povo, para achar A saída mais amena"
}
"Condenado teve Sócrates Trinta dias pra beber A cicuta, o tal veneno Que o faria perecer, Devido ao embate raro Com o monstro 'Minotauro' Que Teseu pôde vencer"


Os sememas que caracterizam discursivamente os atores são: dedicação; injustiça; inimizade; humildade; humanidade; sabedoria; inveja; punição; tristeza. Os temas eufóricos refletem Sócrates, o que confirma a posição favorável do enunciador em relação a ele, posto que desde jovem dedicou-se à busca pela sabedoria, compartilhando seus conhecimentos, sem arrogância, com a população, o que reflete uma atitude humana. Como teve grande destaque, despertou a inveja nos poderosos, adquirindo, dessa forma, muitos inimigos, que planejaram sua prisão. Diante disso, os temas disfóricos estão ligados aos desafetos de Sócrates e a tristeza, sentimento que acometeu seus discípulos após a efetivação de sua pena de morte. Tais temas refletem diretamente na construção dos agonistas, estando os agonistas sábio, humilde e benevolente para Sócrates, o agonista invejoso refere-se aos inimigos do filósofo e o agonista triste, aos seus companheiros de cela. Seguem alguns fragmentos que corroboram:

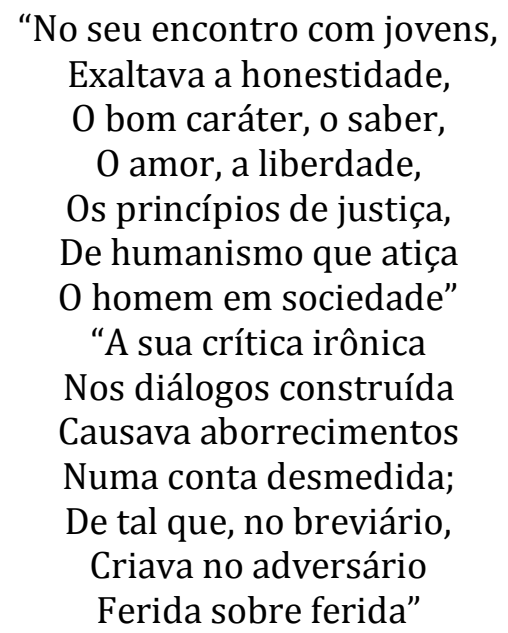

No que diz respeito aos objetos transacionais, a sabedoria era tida como ídolo para os jovens, eles não tinham acesso, era permitido aceitar o que lhes era imposto pelos grandes filósofos pensadores, no entanto, através do método de indução de Sócrates, considerado aqui como fetiche, eles puderam se tornar também pensadores e questionadores das verdades repassadas.

Os conflitos da narrativa são dois: conhecimento versus ignorância e bem versus mal. 0 primeiro deles reflete o objetivo de vida de Sócrates, disseminar o conhecimento para combater a ignorância que atingia os cidadãos gregos, abrindo suas mentes, através do diálogo, sua metodologia de ensino, com relação a assuntos gerais, em especial, religiosos e políticos, cujo propósito principal era 
findar com a tirania dos Estados, que almejava uma população submissa às suas verdades e não questionadora de seus atos. Sendo assim, na tensão dialética, o conhecimento é o contrário de ignorância e o contraditório de não-conhecimento. O conhecimento sem a ignorância resulta na sabedoria. A ignorância tem como seu contrário o conhecimento e, como contraditório, a não-ignorância. A ignorância sem o conhecimento reflete numa população totalmente subordinada ao governo.

Outra tensão que aparece é entre o bem e o mal, representada pela atitude do governo em punir Sócrates, que só tem o intuito de fazer o bem à população, compartilhando seu conhecimento. Por outro lado, o mal é gerado nos poderosos porque consideraram o filósofo como um agitador e contrário ao Estado e, tomados pelo ódio, manipularam uma condenação injusta a Sócrates, a pena de morte. Nessa luta entre o bem e o mal, este vence, através da morte do filósofo. 0 bem, assim sendo, é o contrário de mal e o contraditório de não-bem. 0 bem sem o mal exprime as atitudes de Sócrates. Já o mal é opositor ao bem e tem o seu contraditório em não-mal. 0 mal sem o bem converte-se na punição injusta a Sócrates.

Com a análise, fica perceptível que a figura de Sócrates é construída euforicamente pelo enunciador, que enaltece seu texto a sabedoria e as ações do filósofo, condenando as ações da elite grega.

\section{Conclusão.}

Em linhas gerais, com a análise, fica claro que os atores construídos euforicamente se destacam como os perseguidos por questionarem o sistema que rege a sociedade, caracterizado como uma ditadura intelectual, porquanto o conhecimento fica restrito a um grupo específico, subjugando a população a uma ignorância cultural. Sócrates, percebendo isso, empenha-se em mudar essa realidade, instigando o povo a uma reflexão crítica. Os conflitos e objetos tradicionais seguem a mesma linha, sempre mostrando eufóricos os elementos em torno de Sócrates e, disfóricos, aqueles dos poderosos.

Diante disso, pode-se perceber que os folhetos são grandes difusores da cultura não só popular, mas letrada. Os textos filosóficos, as biografias de pessoas letradas nacionais e estrangeiras bem o comprovam. Pode-se, pois, afirmar que o poeta não é um inculto, como afirmam alguns. Não só possuem uma cultura ampla 
(as leituras de mundo que fazem bem o revelam), mas servem de mediação entre a cultura letrada e a iletrada, entre o escolarizado e o popular.

\section{Referências}

BARROS, Diana Luz Pessoa de. Teoria semiótica do texto. 4. e.d. São Paulo: Ática, 1999.

BATISTA, Maria de Fátima Barbosa. 0 discurso semiótico. In: : ALVES, Eliane Ferraz.

COURTÉS, J. Introdução à semiótica narrativa e discursiva. Almedina, 1979.

FIORIN, José Luiz. Elementos de Análise do Discurso. 13. ed. São Paulo: Contexto, 2005.

As astúcias da enunciação: as categorias de pessoa, espaço e tempo. 2ed. São Paulo: Ática, 2002. 318 p.

FONTANILLE, Jacques. Semiótica do discurso; tradução de Jean Cristtus Portela. São Paulo: Contexto, 2007.

GREIMAS, Algirdas Julien. J. . Os Atuantes, os Atores e as Figuras. IN: Semiótica Narrativa e Textual. São Paulo: Cultrix, 1977.

GREIMAS, A.J \& COURTÉS. Dicionário de semiótica. São Paulo: Contexto, 2008.

Semântica Estrutural. Tradução de Haquira Osakape e Izidoro Blikstein. São Paulo: Cultrix, Ed. da Universidade de São Paulo, 1973.

HJELMSLEV, L. Prolegômenos a uma teoria da linguagem. Tradução de J. Teixeira Neto. São Paulo: Perspectiva, 2003. 147 p.

PAIS, Cimar Teodoro. Considerações sobre a semiótica das culturas, uma ciência da interpretação: inserção cultural, transcodificações transculturais. In: Acta semiótica et Lingvistica. João Pessoa, v. 14, ano 33, n. 1. p. 17-30, 2009.

PAIS, Cidmar Teodoro. Texto, Discurso e Universo de Discurso. IN: Revista Brasileira de Lingüística - SBPL, n 1, v.8. São Paulo: Plêiade, 1995.

RASTIER, François. Ação e sentido por uma semiótica das culturas. Tradução: Maria de Fátima Barbosa de Mesquita Batista. João Pessoa: Ideia/Editora Universitária, 2010.74p.

Semântica dos textos e semiótica. In: Acta semiótica et Lingvistica. João Pessoa, v. 14, n. 2. p. 27-49, 2009.

SAUSSURE. Ferdinand de. Curso de Lingüística Geral. 11. e.d. São Paulo: Cultrix.

$<$ https://memoriasdapoesiapopular.com.br/2014/11/25/poeta-medeiros-braga-sintesebiografica/> . Acesso em 16/12/2018 